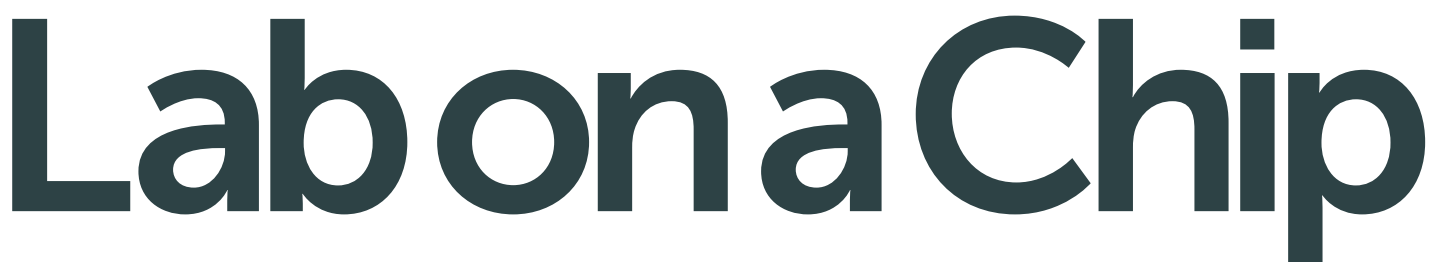

Miniaturisation for chemistry, physics, biology, materials science and bioengineering www.rsc.org/loc
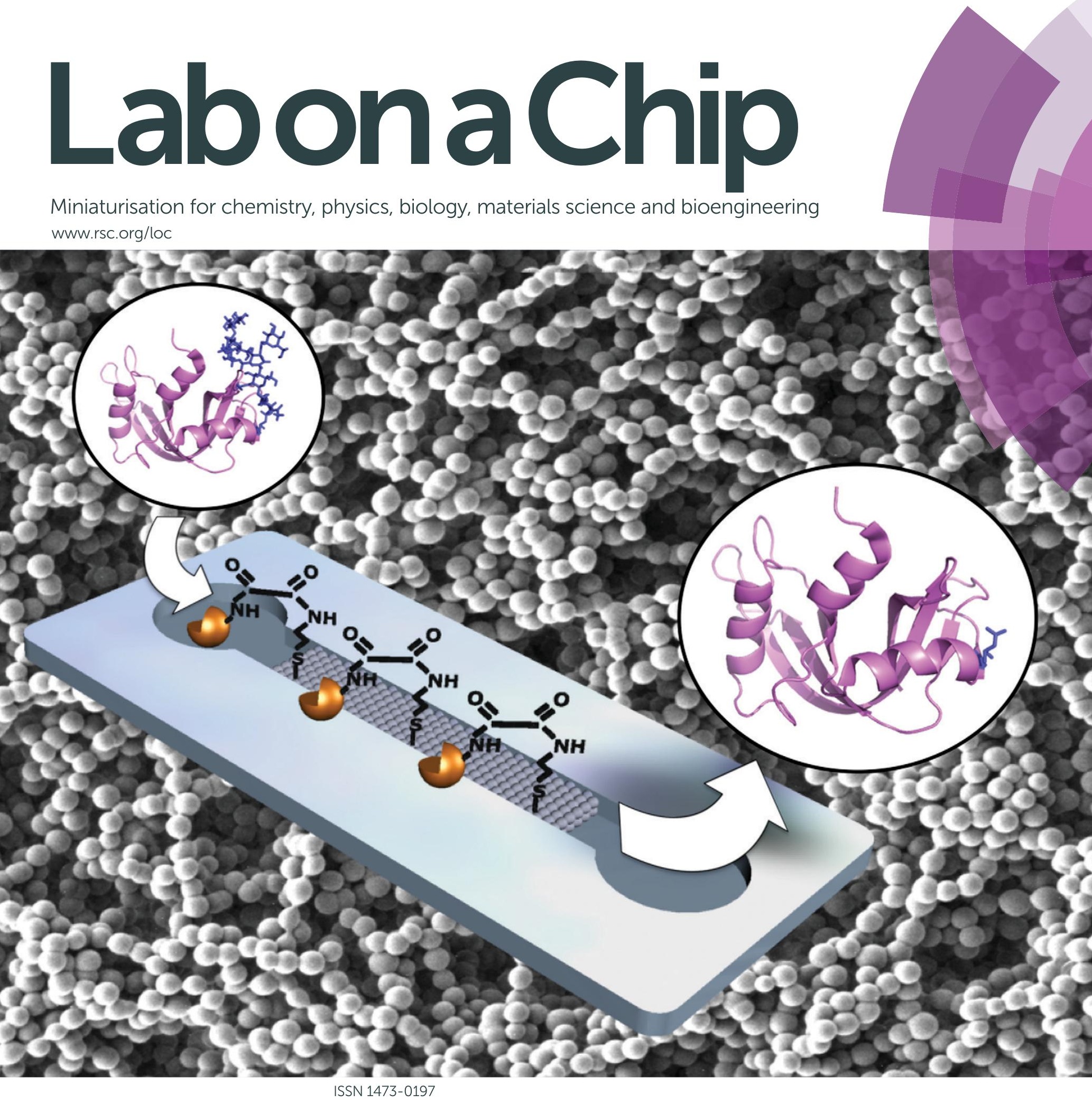


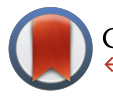

\section{CrossMark}

-click for updates

Cite this: Lab Chip, 2015, 15, 2162

Received 23rd February 2015,

Accepted 26th March 2015

DOI: 10.1039/c5lc00224a

www.rsc.org/loc

\title{
Rapid and simple preparation of thiol-ene emulsion-templated monoliths and their application as enzymatic microreactors $\dagger$
}

\author{
Josiane P. Lafleur, ${ }^{\text {*a }}$ Silja Senkbeil, ${ }^{a}$ Jakub Novotny, ${ }^{\text {bc }}$ Gwenaël Nys, ${ }^{d}$ \\ Nanna Bøgelund, ${ }^{a}$ Kasper D. Rand, ${ }^{a}$ Frantisek Foret ${ }^{c}$ and Jörg P. Kutter ${ }^{a}$
}

\begin{abstract}
A novel, rapid and simple method for the preparation of emulsion-templated monoliths in microfluidic channels based on thiol-ene chemistry is presented. The method allows monolith synthesis and anchoring inside thiol-ene microchannels in a single photoinitiated step. Characterization by scanning electron microscopy showed that the methanol-based emulsion templating process resulted in a network of highly interconnected and regular thiol-ene beads anchored solidly inside thiol-ene microchannels. Surface area measurements indicate that the monoliths are macroporous, with no or little micro- or mesopores. As a demonstration, galactose oxidase and peptide- $N$-glycosidase F (PNGase F) were immobilized at the surface of the synthesized thiol-ene monoliths via two different mechanisms. First, cysteine groups on the protein surface were used for reversible covalent linkage to free thiol functional groups on the monoliths. Second, covalent linkage was achieved via free primary amino groups on the protein surface by means of thiol-ene click chemistry and L-ascorbic acid linkage. Thus prepared galactose oxidase and PNGase F microreactors demonstrated good enzymatic activity in a galactose assay and the deglycosilation of ribonuclease B, respectively.
\end{abstract}

\section{Introduction}

High surface area materials are essential in many chemical, biological and analytical procedures. They can be used as solid supports for biomolecules in enzymatic microreactors, ${ }^{1-3}$ as stationary phases in chromatography ${ }^{4,5}$ and in sample preparation steps such as extraction and preconcentration. ${ }^{6}$ Commercially, sorbents are available as micrometer-sized beads made of materials such as silica or agarose, which can either be bought pre-packed into columns or packed manually. Optimal packing is not trivial to achieve and in practice, even the best packed columns contain 30$40 \%$ void volume in addition to the internal porosity of the beads. ${ }^{7}$ Packing columns in microfluidic chips is even more challenging. Porous polymer monoliths offer an attractive alternative to traditional packed beds. The processability of polymers can be used to easily generate porous monoliths and beads from a mixture of monomers, free radical initiators

\footnotetext{
${ }^{a}$ Department of Pharmacy, University of Copenhagen, Copenhagen, Denmark. E-mail: Josiane.lafleur@sund.ku.dk; Tel: (+45) 35320398

${ }^{b}$ Department of Biological and Biochemical Sciences, University of Pardubice, Pardubice, Czech Republic

${ }^{c}$ Institute of Analytical Chemistry of the ASCR, v.v.i., Brno, Czech Republic

${ }^{d}$ Department of Pharmacy, Université de Liège, Liège, Belgium

$\dagger$ Electronic supplementary information (ESI) available. See DOI: 10.1039/ c5lc00224a
}

and porogenic solvents. Heterogeneous emulsions consisting of at least one immiscible liquid dispersed in another in the form of droplets can be used as templates for the production of porous materials, so-called emulsion-templated monoliths, where either the dispersed or continuous phase is polymerized. ${ }^{8}$ In the case of high internal phase emulsion templated monoliths (polyHIPEs), the internal phase (usually forming more than $74 \% \mathrm{v} / \mathrm{v}$ of the emulsion), is dispersed as discrete droplets within a continuous, less abundant external phase. ${ }^{9}$ These monolithic materials can be prepared using a very simple process carried out within the confines of a closed container, such as a microfluidic channel. However, routine applications in microfluidic devices still face some challenges. Poor adhesion of the monolith inside native unmodified polymeric microchannels and monolith shrinkage are recurring problems. This can cause a formed monolith to detach from the microchannel walls and create, for example, large dead volumes. Therefore, the preparation of porous polymer monoliths and their anchoring inside microfluidic channels is still an active area of research.

The attractive surface properties of thiol-ene (TE) polymers combined with their ease of processing have made them an increasingly popular choice in the fabrication of microfluidic devices for bioanalytical applications. Microfluidic devices have been fabricated with commercially available TE-based photo-curable adhesives (NOA, Norland Optical 
Adhesives, Norland Products Inc, USA $)^{10-16}$ as well as with custom formulations prepared in-house. Alterations in the nature and/or stoichiometry of reactants in customized formulations provide increased control over elastic modulus ${ }^{17}$ and surface chemistry. ${ }^{18}$ Carlborg et $a{ }^{19}{ }^{19}$ introduced a new class of TE materials, "off-stoichiometry" TE (OSTE), achieved by altering extensively the stoichiometric ratios of the initial reactant monomers. The result is a large excess of functional groups, either thiols or enes, on the polymer surfaces and marked variations in material bulk properties. The functional groups present at the surface of OSTE polymers have been used as anchors for the covalent attachment of biomolecules $^{20,21}$ and for bonding. ${ }^{22,23}$

Although TE-based microfluidic devices have received a high level of attention in recent years, the ability of TE polymers to form in-chip porous monoliths remains unexplored. The advantages of TE and OSTE in the preparation of monoliths are numerous. The tunable OSTE surface chemistry can provide for a simple means of covalently anchoring monoliths to microchannel walls without any prior surface activation as well as for a wide variety of photoinitiated functionalization reactions to occur at the surface of the monoliths. Moreover, the TE click chemistry reaction ${ }^{24-26}$ offers high atom economy, a large thermodynamic driving force and simple/mild reaction conditions ${ }^{27}$ as well as bioorthogonality, ${ }^{28}$ making it an ideal reaction scheme for the immobilization of biomolecules on solid supports. ${ }^{20,21,29}$

Immobilized enzyme microreactors are especially interesting since these tend to exhibit much higher efficiency compared to the corresponding reactions in solution. ${ }^{2} \mathrm{~A}$ wide variety of chemical reactions are available for the immobilization of biomolecules to TE solid supports. TE click chemistry allows for simple and rapid photoinitiated modification of the solid support for the covalent irreversible linkage of proteins through their amino groups. Additionally, many enzymes and proteins possess free thiol groups at their surface, which are available for interactions with the thiol groups present at the surface of OSTE monoliths, allowing their straightforward and reversible immobilization through direct disulfide linkage. Finally, in proteins where cysteine residues form intramolecular disulfide bonds, immobilization can proceed through thiol-disulfide exchange ${ }^{30,31}$ or photonic activation of disulfide bridges. ${ }^{32}$ The thiol-disulfide exchange chemistry offers several advantages as covalent disulfide bonds can form efficiently at neutral $\mathrm{pH}$ in aqueous solutions and can be easily reversed with a reducing agent ${ }^{33}$ for the regeneration of the microreactor. TE and thiol-yne (TY) polyHIPEs have been prepared in bulk, ${ }^{34-38}$ with functional monomers added in situ ${ }^{35,37}$ or in a postfunctionalization step performed on the ground monolith powder. ${ }^{38}$ Droplet-based microfluidic devices have been used to prepare NOA porous polymer microspheres ${ }^{39}$ as well as macroporous and non-porous TE/TY polymer beads. ${ }^{40}$ In both cases, droplets were cured individually and collected as beads from the microfluidic device. Finally, Liu et al. used $\mathrm{TE}^{41}$ and $\mathrm{TY}^{42}$ photoinduced polymerization for the preparation of macroporous monoliths in fused-silica capillaries for liquid chromatography.

The method reported here allows monolith synthesis and anchoring inside TE microchannels in a single and rapid photoinitiated step. We demonstrate that the thus prepared monoliths can be post-functionalized reversibly through the formation of disulfide bonds with enzymes or permanently using further photoinitiated TE click chemistry to establish an irreversible covalent linkage to enzymes via their free amino groups. As a demonstration, enzymatic microreactors featuring immobilized galactose oxidase and PNGase F were prepared and characterized by performing a galactose assay and the deglycosylation of ribonuclease B, respectively.

\section{Experimental}

\section{Reagents}

Pentaerythritol-tetrakis(3-mercaptopropionate) ("tetrathiol"), triallyl-1,3,5-triazine-2,4,6(1H,3H,5H)-trione ("triallyl"), 2-(boc amino)ethanethiol, L-ascorbic acid (ASA), galactose-oxidase from Dactylium dendroides $\left[50 \mathrm{U} \mathrm{ml}^{-1}\right]$, horseradish peroxidase (HRP, lyophilized powder, $150 \mathrm{U} \mathrm{mg}^{-1}$ ), PNGase F, ninhydrin, D-galactose, D-(+)-glucose, ribonuclease B (RNase B from bovine pancreas (50 Kunitz units per mg protein)), 10acetyl-3,7-dihydroxyphenoxazine (ADHP), Tween 20 and 5,5'dithiobis(2-nitrobenzoic acid) (DTNB) were obtained from Sigma Aldrich (Brøndby, DK). Lucirin TPO-L (ethyl-2, 4, 6-trimethylbenzoylphenyl phosphinate) was obtained from BASF (Hardmatt, CH). Sylgard 184 - poly(dimethylsiloxane) (PDMS) elastomer kit was obtained from Dow Corning (Midland, MI, USA). Hypermer B246 and Span 80 surfactants were obtained from Croda International Plc (Snaith, UK)

\section{Device fabrication}

A two-step replica molding process was used to fabricate the chips. Chip designs were drawn with computer-aided-design software (Autodesk Inventor Professional 2014, San Rafael, CA, USA). The devices featured channels $500 \mu \mathrm{m}$ wide by 200 $\mu \mathrm{m}$ deep. Chips used for fluorescence measurements featured an $800 \mu \mathrm{m}$ deep detection chamber. The internal volume of the chips was $5 \mu \mathrm{l}$. Micromilled poly(methylmethacrylate) (PMMA) masters as well as poly(tetrafluoroethylene) chip holders featuring injection ports were manufactured by high precision milling (Minitech 3, Minitech Machinery Corp., Norcross, GA, USA). PDMS molds for TE casting were prepared from the PMMA masters and cured at $80{ }^{\circ} \mathrm{C}$ for 2 hours.

The TE monomers (tetrathiol and triallyl) were mixed in various stoichiometric ratios and poured into PDMS molds prior to exposure to UV light $\left(25 \mathrm{~s}, 160 \mathrm{~mW} \mathrm{~cm}^{-2}\right.$ at $365 \mathrm{~nm}$, Dymax EC 5000 Series UV curing flood lamp, Dymax Corp, Torrington, CT). After curing, the TE parts were peeled off from the soft PDMS molds. No photoinitiator was used to minimize chip auto-fluorescence. The absence of photoinitiator was compensated for by the high output of the UV flood lamp at wavelengths below $300 \mathrm{~nm}$. Microfluidic chips 
were bonded immediately after production, while a thin layer of uncured TE is still present at the surface of the TE parts due to the short exposure time and slight oxygen inhibition in the absence of photoinitiator. Prior to bonding, the TE parts were warmed up for 10 minutes in an oven at $80{ }^{\circ} \mathrm{C}$ and placed in conformal contact. A slight pressure was applied on the assembly to ensure uniform sealing and it was exposed to UV light $\left(2 \times 1 \mathrm{~min}, 160 \mathrm{~mW} \mathrm{~cm}^{-2}\right.$ at $\left.365 \mathrm{~nm}\right)$ for bonding. The bonded microfluidic chip was placed in an oven under a weight ( $80{ }^{\circ} \mathrm{C}$ for 2 hours) and allowed to cool overnight before use. The final heating step helps keep the parts soft and in contact with each other to further enhance the bonding.

\section{Monoliths preparation}

Two different types of emulsions were prepared in order to form various in-chip TE monoliths (Fig. 1). The emulsions were prepared with either water or methanol as the porogen, resulting in markedly different monolith morphologies. The monomeric composition of the organic phase of the emulsions consisted of stoichiometric TE (S-TE), offstoichiometric TE featuring 40\% excess thiol groups (OSTEthiol) or off-stoichiometric TE featuring $40 \%$ excess allyl groups (OSTE-allyl). The monolith formation conditions are summarized in Table 1.

TE emulsions with water as the dispersed phase. Water $(75-80 \%$ w/w) was added dropwise to a TE mixture containing a surfactant (Hypermer B246 or Span 80, 3-20\% w/w of organic phase) and stirred using an overhead stirrer (300-500 rpm, 3-10 minutes) in order to create an emulsion with water as the dispersed phase. In some cases, chloroform was added to the organic phase $(50 \% \mathrm{w} / \mathrm{w})$. Photoinitiator $(0.2 \% \mathrm{v} / \mathrm{v}$ Lucirin TPO-L) was added to the mixture prior to injection in a TE microfluidic channel followed by curing under UV collimated light (20 seconds, $20.5 \mathrm{~mW} \mathrm{~cm}^{-2}$ at 365 nm, LS-100-3C2 near UV light source, Bachur \& Associates,
Santa Clara, CA, USA). Sections of the microfluidic chip where no monolith was desired were masked prior to exposure. Unreacted monomers were removed by rinsing thoroughly with distilled deionized water (DDW).

Methanol emulsions with TE as the dispersed phase. TE/ methanol mixtures were magnetically stirred $(60-80 \% \mathrm{w} / \mathrm{w}$ methanol, 1 min magnetic stirring at constant speed) in order to create an emulsion with TE as the dispersed phase. Photoinitiator $(0.2 \% \mathrm{v} / \mathrm{v}$ Lucirin TPO-L) was added to the mixture prior to injection in a TE microfluidic channel followed by curing under UV collimated light (7-20 s, $20.5 \mathrm{~mW} \mathrm{~cm}$ at $365 \mathrm{~nm}$ ). Sections of the microfluidic channel where no monolith was desired were masked prior to exposure. Unreacted monomers and methanol were removed by rinsing thoroughly with DDW using a syringe pump (5 min at $10 \mu \mathrm{L}$ $\min ^{-1}$ ). Microfluidic channels were sealed prior to storage to avoid drying of the monolith.

\section{Monoliths characterization}

Imaging and size distribution. Microfluidic chips containing TE monoliths were pried opened and allowed to dry thoroughly before Scanning Electron Microscope (SEM) imaging. The opened microfluidic chips were taped to 12 mm studs with graphite tape for conductivity. Samples were sputtered with gold (circa $4 \mathrm{~nm}$ ) using a Cressington Sputter Coater 108 (Cressington Scientific Instruments Ltd., Watford, UK) or a Leica EM ACE 200 (Leica Microsystems GmbH, Wetzlar, Germany) and imaged using a TM3030 benchtop SEM (Hitachi High-Technologies Europe GmbH, Krefeld, Germany) or an XL 30 FEG-SEM (Philips FEI, Oregon, USA). Particle size distribution was determined by measuring the diameter of the individual beads with ImageJ (ImageJ, U. S. National Institutes of Health, Bethesda, MD, USA) with $N=$ 119-241 measured beads per sample. The means of the distribution were compared by performing a single factor ANOVA test (alpha $=0.05)$. a)

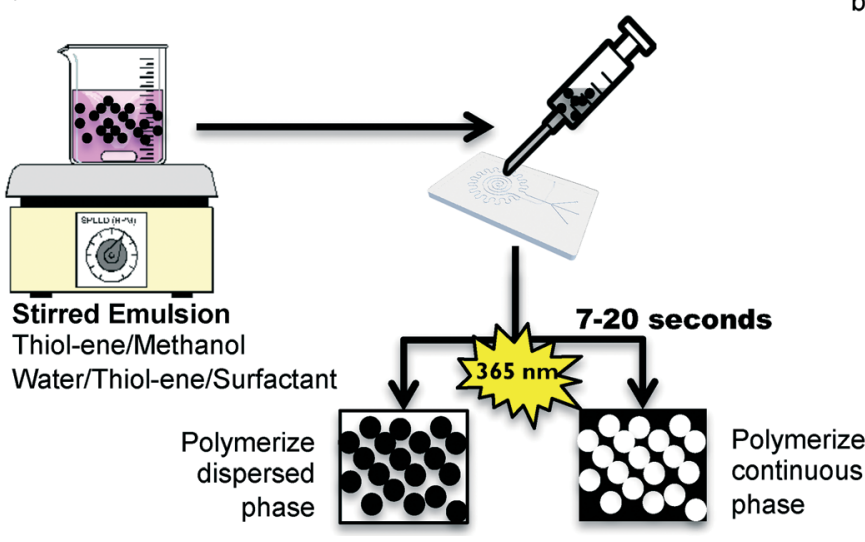

b)
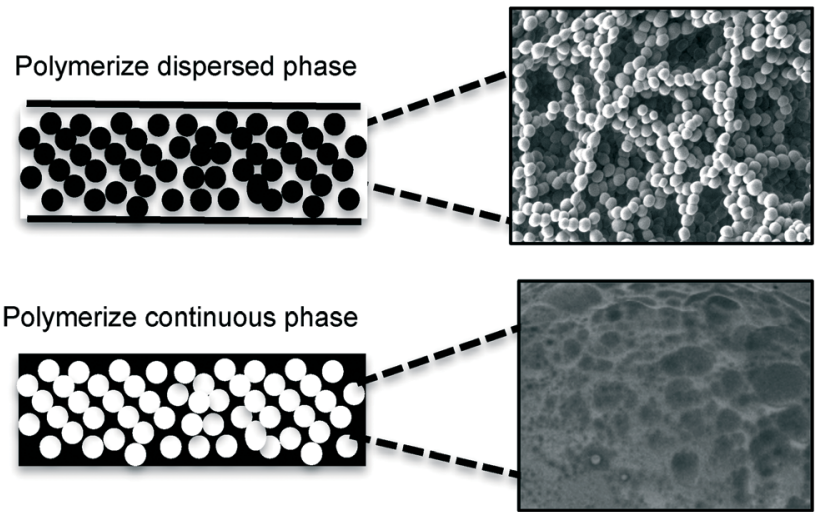

Fig. 1 Monolith preparation procedure. a) The emulsions are stirred with a magnetic mixer or an overhead mixer prior to injection in a TE microfluidic chip and exposure to UV light. b) Depending on the surfactant and porogen present in the emulsion, the TE forms either the dispersed or the continuous phase. 
Table 1 Summary of the monolith formation conditions. All monolith emulsions contained $0.2 \% \mathrm{v} / \mathrm{v}$ Lucirin TPO-L as a photoinitiator and were cured $7-20 \mathrm{~s}\left(20.5 \mathrm{~mW} \mathrm{~cm}^{-2}\right.$ at $\left.365 \mathrm{~nm}\right)$

\begin{tabular}{|c|c|c|c|c|c|}
\hline $\begin{array}{l}\text { Stirring } \\
\text { conditions }\end{array}$ & Stirring time & Porogen & Surfactant & $\begin{array}{l}\text { Polymer } \\
\text { phase }\end{array}$ & Experiments performed \\
\hline \multicolumn{6}{|c|}{ Interconnected beads (polymerized dispersed phase) } \\
\hline $\begin{array}{l}\mathrm{MS}^{a} 40 \% \\
\text { of max. } \\
\text { speed }\end{array}$ & $1 \mathrm{~min}$ & $\begin{array}{l}60 \% \mathrm{w} / \mathrm{w} \\
\text { methanol }\end{array}$ & None & $\begin{array}{l}\text { S-TE } \\
\text { OSTE-allyl } \\
\text { OSTE-thiol }\end{array}$ & Specific surface area \\
\hline $\begin{array}{l}\operatorname{MS}^{a} 40 \% \\
\text { of max. } \\
\text { speed }\end{array}$ & $1 \mathrm{~min}$ & $\begin{array}{l}80 \% \mathrm{w} / \mathrm{w} \\
\text { methanol }\end{array}$ & None & $\begin{array}{l}\text { S-TE } \\
\text { OSTE-allyl } \\
\text { OSTE-thiol }\end{array}$ & $\begin{array}{l}\text { Specific surface area, SEM, enzyme } \\
\text { immobilization, removal of enzymes bound } \\
\text { through thiols with TCEP }\end{array}$ \\
\hline $\begin{array}{l}\operatorname{MS}^{a} 60 \% \\
\text { of max. } \\
\text { speed }\end{array}$ & $1 \mathrm{~min}$ & $\begin{array}{l}80 \% \mathrm{w} / \mathrm{w} \\
\text { methanol }\end{array}$ & None & $\begin{array}{l}\text { S-TE } \\
\text { OSTE-allyl } \\
\text { OSTE-thiol }\end{array}$ & SEM \\
\hline \multicolumn{6}{|c|}{ PolyHIPE (polymerized continuous phase) } \\
\hline $\begin{array}{l}\mathrm{MS}^{a} \quad 40 \% \\
\text { of max. } \\
\text { speed }\end{array}$ & $3-10 \min ^{c}$ & $\begin{array}{l}75 \% \mathrm{w} / \mathrm{w} \\
\text { water }\end{array}$ & $\begin{array}{l}10 \% \mathrm{w} / \mathrm{w} \\
\text { Span } 80\end{array}$ & $\begin{array}{l}\mathrm{S}-\mathrm{TE}+50 \% \\
\mathrm{w} / \mathrm{w} \mathrm{CHCl}_{3}\end{array}$ & (Unstable emulsions) \\
\hline $\begin{array}{l}\text { MS }^{a} 40 \% \\
\text { of max. } \\
\text { speed }\end{array}$ & $3-10 \min ^{c}$ & $\begin{array}{l}80 \% \mathrm{w} / \mathrm{w} \\
\text { water }\end{array}$ & $\begin{array}{l}3 \% \text { w/w } \\
\text { Span } 80\end{array}$ & $\begin{array}{l}\mathrm{S}-\mathrm{TE}+50 \% \\
\mathrm{w} / \mathrm{w} \mathrm{CHCl}_{3}\end{array}$ & (Unstable emulsions) SEM \\
\hline $\begin{array}{l}\text { MS }^{a} 40 \% \\
\text { of max. } \\
\text { speed }\end{array}$ & $3-10 \min ^{c}$ & $\begin{array}{l}80 \% \mathrm{w} / \mathrm{w} \\
\text { water }\end{array}$ & $\begin{array}{l}20 \% \mathrm{w} / \mathrm{w} \\
\text { Span } 80\end{array}$ & $\begin{array}{l}\mathrm{S}-\mathrm{TE}+50 \% \\
\text { w/w } \mathrm{CHCl}_{3}\end{array}$ & (Unstable emulsions) \\
\hline $\begin{array}{ll}\mathrm{OH}^{b} & 500 \\
\mathrm{rpm} & \end{array}$ & $3-10 \min ^{c}$ & $\begin{array}{l}80 \% \mathrm{w} / \mathrm{w} \\
\text { water }\end{array}$ & $\begin{array}{l}10 \% \mathrm{w} / \mathrm{w} \\
\text { Span } 80\end{array}$ & $\begin{array}{l}\mathrm{S}-\mathrm{TE}+50 \% \\
\mathrm{w} / \mathrm{w} \mathrm{CHCl}_{3}\end{array}$ & (Unstable emulsions) \\
\hline $\begin{array}{ll}\mathrm{OH}^{b} & 500 \\
\mathrm{rpm} & \end{array}$ & $3-10 \min ^{c}$ & $\begin{array}{l}75 \% \mathrm{w} / \mathrm{w} \\
\text { water }\end{array}$ & $\begin{array}{l}10 \% \text { w/w } \\
\text { Hypermer B246 }\end{array}$ & $\begin{array}{l}\text { S-TE + 50\% } \\
\text { w/w } \mathrm{CHCl}_{3}\end{array}$ & (Unstable emulsions) \\
\hline $\begin{array}{l}\mathrm{OH}^{b} \quad 300 \\
\mathrm{rpm}\end{array}$ & $3-10 \min ^{c}$ & $\begin{array}{l}80 \% \mathrm{w} / \mathrm{w} \\
\text { water }\end{array}$ & $\begin{array}{l}3 \% \mathrm{w} / \mathrm{w} \\
\text { Hypermer B246 }\end{array}$ & $\begin{array}{l}\mathrm{S}-\mathrm{TE}+50 \% \\
\mathrm{w} / \mathrm{w} \mathrm{CHCl}_{3}\end{array}$ & (Unstable emulsions) \\
\hline
\end{tabular}

Surface area analysis. TE monoliths (S-TE as the dispersed phase, $60 \%$ and $80 \%$ methanol emulsions) were prepared in bulk and cured as pellets in Eppendorf Tubes ${ }^{\circledR}$. Gas (krypton) adsorption measurements were performed at $77 \mathrm{~K}$ using a Quantachrome Autosorb-1 Sorption Analyzer (Quantachrome GmbH \& Co, Odelzhausen, Germany) and the specific surface area was determined by Brunauer-EmmettTeller (BET) analysis. Prior to the measurements, bulk monolith samples were degassed under vacuum $\left(40{ }^{\circ} \mathrm{C},<10^{-3}\right.$ torr $)$ for 24 hours. For all samples, the BET plots were linear $\left(R^{2}>\right.$ 0.999) in the relative pressure range of $0.1<P / P_{0}<0.3$, confirming the applicability of the BET equation. The specific surface area was determined from the krypton adsorption isotherm using the BET equation. ${ }^{43}$

\section{Thiol surface density}

The surface thiol density was quantitated using DTNB in a protocol adapted from Ellman's procedure for quantifying free sulfhydryl group in solution ${ }^{44}$ and described elsewhere. ${ }^{20}$ Briefly, thiol-ene slabs $(20 \mathrm{~mm} \times 20 \mathrm{~mm} \times 0.5 \mathrm{~mm}, 60 \%$ excess allyl - $60 \%$ excess thiols) were immersed in 5,5'dithiobis(2-nitrobenzoic acid) $\left(0.08 \mathrm{mg} \mathrm{mL}^{-1}\right.$ in $0.1 \mathrm{M}$ sodium phosphate buffer, pH 8.0). After 10 minutes, the thiol-ene slab was removed and the absorbance of the solution was measured at $412 \mathrm{~nm}$. The number of thiols on the surface of the thiol-ene slabs was evaluated from the molar extinction coefficient of $\mathrm{TNB}^{2-}\left(14150 \mathrm{M}^{-1} \mathrm{~cm}^{-1}\right) .{ }^{45}$

\section{Enzyme immobilization}

Two different immobilization schemes were used to link the enzymes to the monoliths. Table 2 summarizes the enzyme immobilization experiments performed.

Immobilization on unmodified TE monoliths. Immobilization on unmodified TE monoliths was achieved by applying the enzyme solution $\left(1 \mathrm{mg} \mathrm{ml}^{-1}\right.$ PNGase $\mathrm{F}$ in $50 \mathrm{mM}$ ammonium bicarbonate buffer at $\mathrm{pH} 8.0,0.14 \mathrm{mg} \mathrm{ml}^{-1}, 50 \mathrm{U} \mathrm{mL}^{-1}$ for galactose oxidase in $50 \mathrm{mM}$ Tris- $\mathrm{HCl}$ buffer at $\mathrm{pH} 8.0$ ) to the monolith and incubating overnight at $4{ }^{\circ} \mathrm{C}$.

Immobilization on OSTE-allyl monoliths via TE click chemistry and ASA linkage. Immobilization on OSTE-allyl monoliths was achieved using a two-step reaction scheme. Free amine groups were introduced at the surface of the monolith using a TE click photochemical reaction between the thiol group of cystamine and the excess ene groups at the surface of the OSTE monolith in a procedure adapted from Magenau et al. ${ }^{46}$ The amine group of the cysteamine was protected with a tert-butoxycarbonyl ( $t$-Boc) group to reduce thiolate formation and favor the TE click reaction. $200 \mu \mathrm{L}$ of 2-(boc amino)ethanethiol containing $0.5 \% \mathrm{v} / \mathrm{v}$ photoinitiator (Lucirin TPO-L) was injected on the monolith. Channel sections where no functionalization was desired were masked prior to exposure under collimated UV light (30 seconds exposure, $20.5 \mathrm{~mW} \mathrm{~cm} \mathrm{~cm}^{-2}$ at $365 \mathrm{~nm}$ ). After exposure, unreacted products were removed by flushing with $0.05 \%$ Tween 20 in DDW ( 5 min, $50 \mu \mathrm{l} \mathrm{min}^{-1}$ ). 
Table 2 Summary of the enzyme immobilization experiments. All monoliths were prepared from emulsions where TE forms the dispersed phase (interconnected beads) with $80 \% \mathrm{w} / \mathrm{w}$ methanol as the continuous phase, $0.2 \% \mathrm{v} / \mathrm{v}$ Lucirin TPO-L as the photoinitiotor and magnetic stirring for $1 \mathrm{~min}$ ( $40 \%$ of max. stirring speed)

\begin{tabular}{llll}
\hline Immobilized enzyme & Monolith curing time & \\
\hline Galactose oxidase & $7 \mathrm{~s}$ & Monolith composition & Immobilization scheme \\
Galactose oxidase & $7 \mathrm{~s}$ & OSTE-allyl $(40 \%$ excess ene) & TE click chemistry ${ }^{a}$ and ASA linkage \\
Galactose oxidase & $20 \mathrm{~s}$ & OSTE-allyl $(40 \%$ excess ene $)$ & Unmodified TE, overnight incubation with enzyme \\
Galactose oxidase & $20 \mathrm{~s}$ & OSTE-thiol $(40 \%$ excess thiol) & Unmodified TE, overnight incubation with enzyme \\
PNGase F & $7 \mathrm{~s}$ & S-TE & Unmodified TE, overnight incubation with enzyme $^{a}$ and ASA linkage
\end{tabular}

a $20.5 \mathrm{~mW} \mathrm{~cm}^{-2}$ at $365 \mathrm{~nm}$.

Following the photografting step, deprotection of the amine groups to reveal an $\mathrm{NH}_{2}$-functionalized monolith was achieved by flushing the monolith with dilute hydrochloric acid overnight ( $4 \mathrm{M}, 12$ hours at $4 \mu \mathrm{min}^{-1}$ ) using NeMESYS high precision syringe pumps (Cetoni GmBH, Korbußen, Germany). Deprotection conditions were optimized on TE slabs using a procedure adapted from Patton et al. ${ }^{47} \mathrm{~A} 0.2 \%$ ethanolic ninhydrin solution was deposited on the deprotected TE polymer and heated at $110{ }^{\circ} \mathrm{C}$ for 7 minutes revealing a blue color in the presence of free amine groups, indicating successful deprotection.

Galactose oxidase and PNGase F were subsequently covalently immobilized on the $\mathrm{NH}_{2}$-monoliths by means of an L-ascorbic acid (ASA) linkage in a procedure adapted from Tiller et $a l^{48}$ The ASA can work as a di-keto coupling agent between the free amine groups on the surface of the monolith and the free primary amino groups of the enzymes to be immobilized. A solution of ASA ( $1 \% \mathrm{w} / \mathrm{v}$ in methanol) was applied on the $\mathrm{NH}_{2}$-monolith and the channel was sealed and left to incubate for 30 minutes. Unreacted products were flushed with DDW (5 min, $30 \mu \mathrm{L} \mathrm{min}{ }^{-1}$ ). The channels were then filled with enzyme solution (galactose oxidase, $50 \mathrm{U}$ $\mathrm{mL}^{-1}$ in DDW or PNGase F, $50 \mathrm{U} \mathrm{mL}^{-1}$ in DDW), sealed and left to incubate ( 24 hours at $4{ }^{\circ} \mathrm{C}$ ). Unreacted enzymes were removed by rinsing thoroughly with DDW using a syringe pump (5 min, $\left.30 \mu \mathrm{L} \mathrm{min}^{-1}\right)$.

\section{Reduction of disulfide bonds for enzyme removal}

The monoliths featuring galactose oxidase were flushed for one hour at $50 \mu \mathrm{min}^{-1}$ with the reducing agent $2 \mathrm{mM}$ tris(2carboxyethyl)phosphine (TCEP) to remove enzymes immobilized via the formation of disulfide bonds.

\section{Enzymatic reactions}

Deglycosylation of ribonuclease $\mathrm{B}$ using the PNGase $\mathrm{F}$ microreactor. The PNGase F enzymatic microreactor was conditioned with ammonium bicarbonate buffer $(5 \mathrm{~min}$ at $30 \mu \mathrm{L}$ $\min ^{-1}$ ). The denatured and reduced glycoprotein solution $\left(1 \mathrm{mg} \mathrm{ml}{ }^{-1}\right.$ ribonuclease B in $50 \mathrm{mM}$ ammonium bicarbonate buffer with $5 \mathrm{mM}$ TCEP-HCl, heated to $100{ }^{\circ} \mathrm{C}$ for $10 \mathrm{~min}$ ) was applied to the enzymatic microreactor and collected at the outlet using a vacuum pick-up tool connected in series with a custom-made collection trap and a vacuum pump.

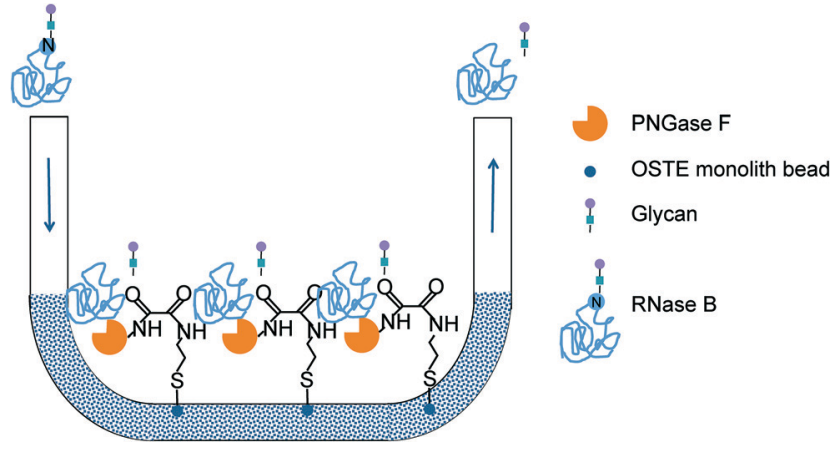

Fig. 2 Deglycosylation of RNase $B$ on the enzymatic microreactor featuring PNGase F immobilized via thiol-ene click chemistry and ASA linkage.

Similarly, batch mode samples were processed by mixing the denatured and reduced ribonuclease $\mathrm{B}\left(20 \mu \mathrm{l}, 1 \mathrm{mg} \mathrm{ml}^{-1}\right)$ with PNGase $\mathrm{F}\left(2 \mu \mathrm{l}, 500 \mathrm{U} \mathrm{ml}^{-1}\right)$ for 2 hours at $37{ }^{\circ} \mathrm{C}$. The reaction was stopped by immersion in a hot water bath $\left(100{ }^{\circ} \mathrm{C}, 5 \mathrm{~min}\right)$. The reaction scheme is illustrated schematically in Fig. 2.

HPLC and mass spectrometry. The microreactordeglycosylated ribonuclease B samples $(50$ pmol $)$ were injected manually onto a Waters Acquity HPLC system (Waters Coproration, Milford, MA, USA) equipped with a 6-port switching valve (Rheodyne Model 7125) featuring an in-house packed microbore reversed-phase trap column ( $0.5 \mathrm{~mm}$ ID $2 \mathrm{~mm}$, Poros $10 \mathrm{R} 1$ ) in the sample loop. The trap column was pre-flushed in load position by manual injection of formic acid (600 $\mu \mathrm{l}, 0.23 \%)$, followed by injection of the protein sample and finally washing of the trap column with formic acid $(800 \mu \mathrm{l}, 0.23 \%)$. Upon switching to the elute position, the protein retained on the trap was eluted isocratically to the mass spectrometer $(0.23 \%$ formic acid in $90 \%$ acetonitrile, $0.040 \mathrm{ml} \mathrm{min}^{-1}$ ).

Positive ion-electrospray ionization mass spectra were acquired on a Waters SynaptG2 mass spectrometer (Waters Corporation, Milford, MA, USA) coupled to the HPLC system. Mass spectra were processed using the MassLynx software (Waters Corp, Milford, MA). The activity of PNGase F was assessed by comparing the intensity of RNase peaks ([M + $15 \mathrm{H}]^{15+}$ for glycosylated and deglycosylated species) from a non-deglycosylated sample as well as for samples subjected to off-line and on-chip deglycosylation with PNGase F. 
Table 3 Summary of the reactions performed on the monoliths

\begin{tabular}{|c|c|c|c|}
\hline Step & Reagents & Conditions & Outcome \\
\hline \multicolumn{4}{|c|}{ Immobilization via TE click chemistry and ASA linkage } \\
\hline Photografting & $200 \mu \mathrm{L} 2$-(Boc amino)ethandiol $+0.5 \% \mathrm{v} / \mathrm{v}$ TPO-L & $\begin{array}{l}\text { UV } \\
\text { exposure, } 30 \mathrm{~s}\end{array}$ & $\begin{array}{l}\text { The monolith features } t \text {-Boc protected } \\
\text { amino groups }\end{array}$ \\
\hline Flushing & $0.05 \%$ Tween 20 in DDW & $\begin{array}{l}5 \mathrm{~min}, 50 \mu \mathrm{L} \\
\min ^{-1}\end{array}$ & Removal of unreacted products \\
\hline Deprotection & $4 \mathrm{M} \mathrm{HCl}$ & $\begin{array}{l}12 \mathrm{~h}, 4 \mu \mathrm{L} \\
\min ^{-1}\end{array}$ & $\begin{array}{l}\text { Removal of } t \text {-Boc protecting group to } \\
\text { reveal amino groups at the monolith } \\
\text { surface }\end{array}$ \\
\hline Incubation & $1 \% \mathrm{w} / \mathrm{v}$ ASA in $\mathrm{MeOH}$ & $30 \mathrm{~min}$ & Coupling of ASA to amino groups on the monoliths \\
\hline Flushing & DDW & $\begin{array}{l}5 \min , 30 \mu \mathrm{L} \\
\min ^{-1}\end{array}$ & Removal of unreacted products \\
\hline Incubation & Galactose oxidase/PNGase F & $\begin{array}{l}\text { Overnight, } 4 \\
{ }^{\circ} \mathrm{C}\end{array}$ & $\begin{array}{l}\text { Coupling between immobilized ASA and } \\
\text { the free primary amino groups of the } \\
\text { enzymes }\end{array}$ \\
\hline Flushing & DDW & $\begin{array}{l}5 \min , 30 \mu \mathrm{L} \\
\min ^{-1}\end{array}$ & Removal of unreacted groups \\
\hline \multicolumn{4}{|c|}{ Immobilization via free thiols (galactose oxidase microreactor) } \\
\hline Incubation & $\begin{array}{l}\text { Galactose oxidase }\left(0.14 \mathrm{mg} \mathrm{ml}^{-1}, 50 \mathrm{U} \mathrm{mL}^{-1}\right) \text { in } 50 \mathrm{mM} \\
\text { Tris-HCl buffer, pH } 8.0\end{array}$ & $\begin{array}{l}\text { Overnight, } 4 \\
{ }^{\circ} \mathrm{C}\end{array}$ & $\begin{array}{l}\text { Reversible covalent linkage between } \\
\text { cysteine groups on the enzyme and free } \\
\text { thiols on the monolith }\end{array}$ \\
\hline \multicolumn{4}{|c|}{ Reduction of disulfide bonds (galactose oxidase microreactor) } \\
\hline Flushing & $2 \mathrm{mM}$ TCEP & $\begin{array}{l}1 \mathrm{~h}, 50 \mu \mathrm{L} \\
\min ^{-1}\end{array}$ & $\begin{array}{l}\text { Removal of enzymes immobilized via the formation } \\
\text { of disulfide bonds }\end{array}$ \\
\hline \multicolumn{4}{|c|}{ D-Galactose assay (galactose oxidase microreactor) } \\
\hline Incubation & $\begin{array}{l}50 \mu \mathrm{M} \text { D-galactose, } 25 \mu \mathrm{M} \text { ADHP, } 0.01 \mathrm{U} \mathrm{ml}^{-1} \mathrm{HRP} \text { in } \\
\text { Tris-HCl buffer (pH 8.0) }\end{array}$ & $30 \mathrm{~min}, 37^{\circ} \mathrm{C}$ & $\begin{array}{l}\text { Oxidation of D-galactose and production } \\
\text { of } \mathrm{H}_{2} \mathrm{O}_{2} \text {. Oxidation of ADHP into fluorescent resorufin }\end{array}$ \\
\hline \multicolumn{4}{|c|}{ Deglycosylation of RNase B (PNGase F microreactor) } \\
\hline Conditioning & $50 \mathrm{mM}$ ammonium bicarbonate buffer & $\begin{array}{l}5 \min ^{-1}, 30 \mu \mathrm{L} \\
\min ^{-1}\end{array}$ & Monolith conditioning \\
\hline Deglycosylation & $\begin{array}{l}\text { Ribonuclease } \mathrm{B}\left(1 \mathrm{mg} \mathrm{ml}^{-1} \text { in } 50 \mathrm{mM} \text { ammonium }\right. \\
\text { bicarbonate buffer) with } 5 \mathrm{mM} \text { TCEP-HCl heated to } \\
100^{\circ} \mathrm{C} \text { for } 10 \mathrm{~min}\end{array}$ & $\begin{array}{l}\text { Gentle } \\
\text { suction } \\
\text { applied }\end{array}$ & Collection of the deglycosylated products \\
\hline
\end{tabular}

D-Galactose assay using the galactose oxidase enzymatic microreactor. The galactose detection protocol was adapted from Sigma-Aldrich's galactose assay (Galactose Assay Kit MAK012) and optimized for microfluidic application. The microreactors were filled with the working solution $(50 \mu \mathrm{M}$ D-galactose, $25 \quad \mu \mathrm{M}$ 10-acetyl-3,7-dihydroxyphenoxazine (ADHP) and $0.01 \mathrm{U} \mathrm{ml}^{-1} \mathrm{HRP}$ in tris/HCl buffer, $\mathrm{pH} \mathrm{8.0),} \mathrm{and}$ incubated (30 $\mathrm{min}$ at $37^{\circ} \mathrm{C}$ ). D-Galactose is oxidized into D-galacto-hexodialdose by the monolith-immobilized enzyme producing hydrogen peroxide. In the presence of hydrogen peroxide, HRP catalyses the oxidation of non-fluorescent ADHP into the fluorescent product resorufin. The fluorescence of resorufin ( $\left.\lambda_{\mathrm{ex}} 530-560 \mathrm{~nm}, \lambda_{\mathrm{em}} 590 \mathrm{~nm}\right)$ was recorded with an inverted microscope (IX71, Olympus Corporation, Tokyo, Japan) equipped with a Canon 550D (Tokyo, Japan) digital camera. Images were acquired in 14 bit RAW format and image analysis was performed with Matlab (MathWorks, Natick, MA, USA). All results were blank corrected and normalized to a control (working solution and $50 \mathrm{U} \mathrm{ml}^{-1}$ galactose-oxidase).

Microreactors were stored $3-13$ days in DDW $\left(4^{\circ} \mathrm{C}\right)$ to assess the impact of storage time on performance. The fluorescence intensity of resorufin obtained before and after storage was compared. The ability of the microreactors to be re-used was also evaluated. Microreactors were thoroughly washed $(0.05 \%$ Tween 20 in DDW) to remove all the fluorescence products between each successive use and reused up to 5 times at 3 day intervals.

The immobilization and enzymatic reaction schemes performed on the monoliths are summarized in Table 3.

\section{Results and discussion}

\section{Monolith characterization}

TE emulsions with water as the dispersed phase resulting in foam-like TE monoliths. High internal phase TE emulsions

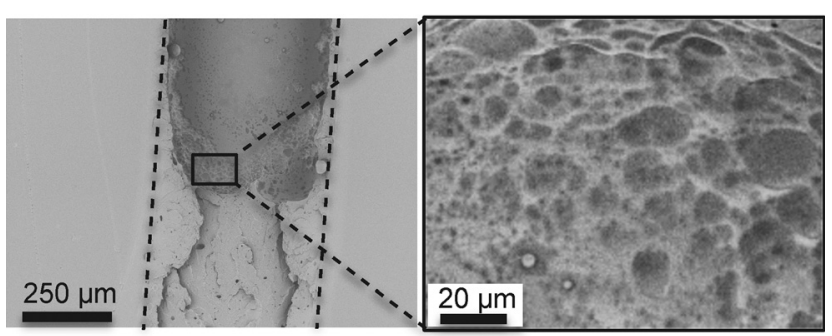

Fig. 3 TE monolith where water forms the dispersed phase. (Left) The monolith is shown inside the channel after the top layer of the chip has been removed. Dashed lines have been added to highlight the channel walls. The upper darker half of the channel is empty. (Right) Magnified view of the monolith's cross section. The emulsion consisted of $80 \%$ water $\mathrm{w} / \mathrm{w}$ while the organic phase consisted of $\mathrm{S}-\mathrm{TE}$, chloroform (50\% w/w of the organic phase) Span $80(3 \% \mathrm{w} / \mathrm{w}$ of organic phase) and a photoinitiator (Lucirin TPO-L, $0.2 \% \mathrm{v} / \mathrm{v}$ ). 
(polyHIPEs) in which water formed $75-80 \%$ of the emulsion were prepared using either Span 80 or Hypermer B246 as a surfactant. As seen in Fig. 3 (Left), the polyHIPE monoliths formed a very strong bond with the channel walls and chip cover, resulting in a smooth pore-free TE layer at the top of the monolith where the TE microfluidic chip cover used to be. Since chips and monoliths are made out of the same material, the uncured monoliths fused seamlessly with the microchannel walls, creating an extremely strong anchoring upon curing. The magnified view of the monolith's crosssection (Fig. 3 (Right)) reveals that the monolith remains intact and porous in its center. This type of polyHIPEs based on TE chemistry have been reported previously for bulk preparations. ${ }^{34-38}$ However, the scaling down of the process proved to be difficult and irreproducible for applications in microfluidic devices. PolyHIPEs form highly viscous, paste-like emulsions ${ }^{9}$ which are difficult to inject inside microchannels and the emulsification process can take up to $60 \mathrm{~min} .{ }^{36}$ Emulsions containing various concentrations of surfactants and organic phase modifiers mixed for shorter times with an overhead mixer were unstable. Since the preparation of polyHIPEs was inconsistent with rapid, reproducible and simple monolith preparation, all subsequent experiments (characterization and enzymatic microreactors) were performed with the second type of emulsion investigated, where the TE forms the dispersed phase in methanol.

Emulsions with TE as the dispersed phase resulting in bead-like TE monoliths. The second type of emulsion proved to be more adequate for applications in microfluidic devices. This type of emulsion required less than a minute of stirring with a magnetic stir bar and resulted in a network of highly regular interconnected beads (Fig. 4a)) with interstitial macropores $0.5-5 \mu \mathrm{m}$ in diameter depending on the preparation conditions. The emulsions were stable, showing no or little coalescence of droplets prior to curing and their low viscosity made introduction inside TE microfluidic channels possible by simple capillary action although external pressure was applied for more consistency. The size of the beads as well as the density of their packing was highly dependent upon the preparation conditions as shown in Fig. 4b) and c), where higher stirring speeds result in smaller, more densely packed beads. No significant differences could be seen in the appearance of the monoliths based on variations in the

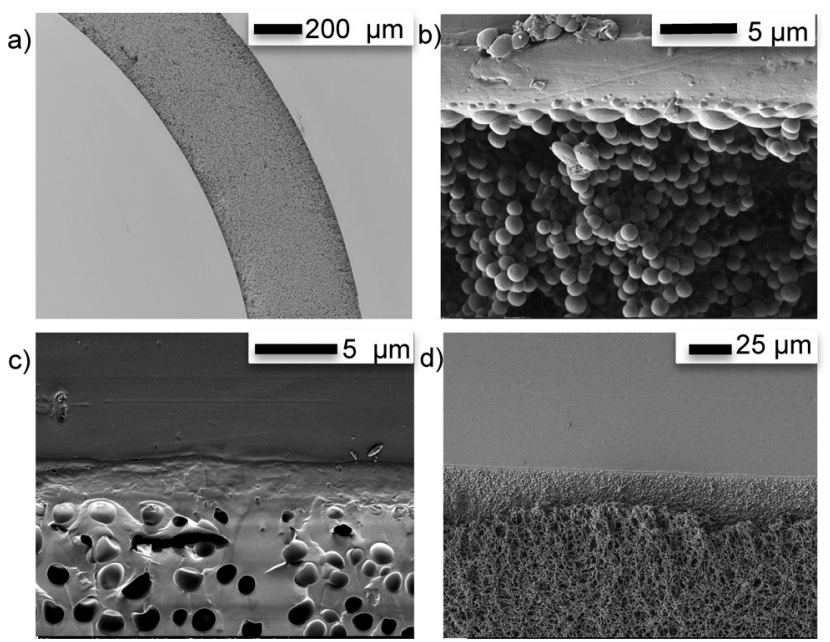

Fig. 5 Emulsions with TE as the dispersed phase in methanol forming bead-like monoliths. The top covers have been pried open and the monoliths thoroughly dried prior to imaging. All images represent a top view of the channel. a) The network of beads fills up the microchannel uniformly. b) The TE beads fuse seamlessly with the channel walls to provide a strong anchoring. c) Smooth TE layer observed at the interface between the TE monolith and TE chip top cover. d) The monoliths exhibit slight shrinkage upon drying and can break away from the chip walls.
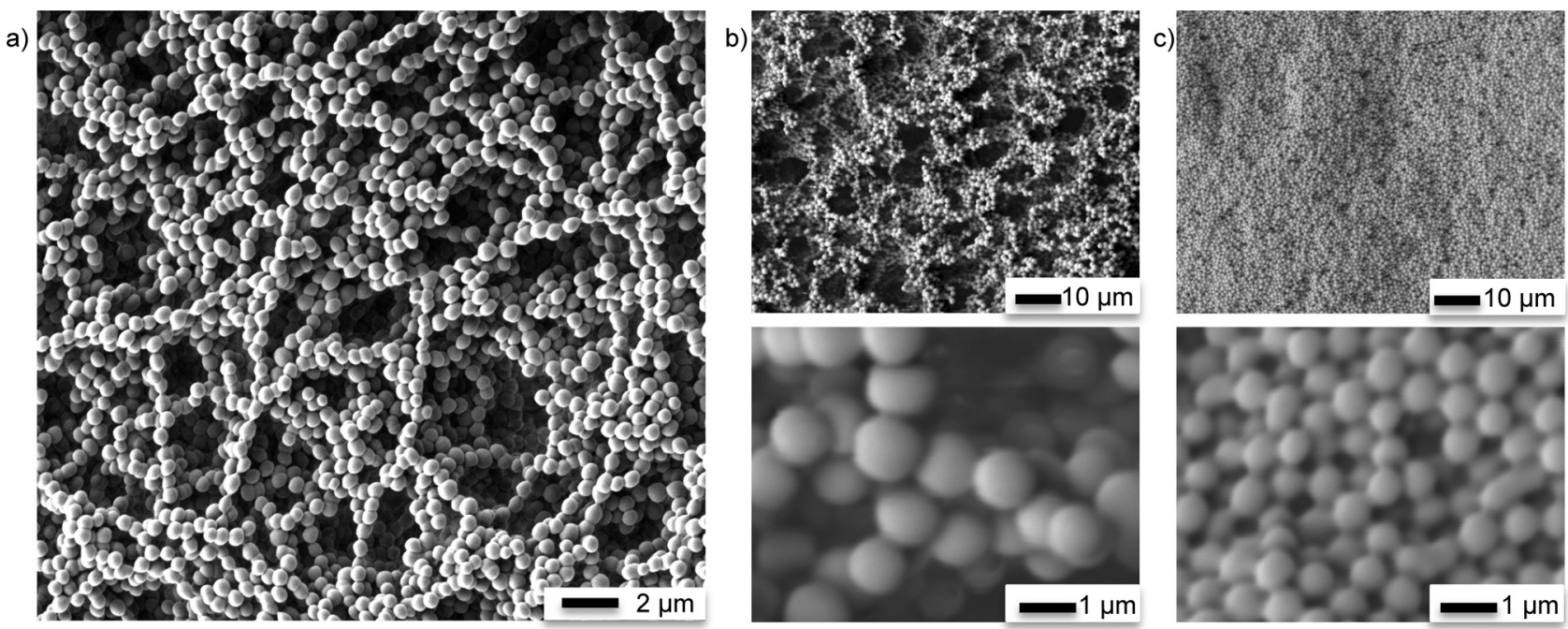

Fig. 4 a) Monoliths in which TE constituted the dispersed phase in methanol ( $80 \%$ methanol used as a porogen) formed a network of highly regular interconnected beads. b) Loosely packed larger $($ ca. $1 \mu \mathrm{m})$ beads are obtained at a lower stirring speeds $(40 \%$ of maximum stirring intensity). c) Smaller (ca. $750 \mathrm{~nm}$ ) more tightly packed beads can be obtained at higher stirring speeds (60\% of maximum stirring intensity). 
stoichiometric composition of the TE monomers. All characterization experiments were performed on S-TE monoliths.

As shown in Fig. 5a), the methanol/TE emulsions filled the channel completely and uniformly and the TE beads fused with the microchannel walls (Fig. 5b)), providing strong anchoring of the monolith. At the interface between the monolith and the TE microchannel walls, a smooth TE film resulting from the fusing of the beads with the wall can be observed (Fig. 5c)). This fusing of the monolith beads with the surrounding TE chip walls was independent of the stoichiometric composition of either the TE monolith, or the TE chip. Therefore, TE monoliths can be covalently anchored to TE microchannel walls without any prior surface activation, independently of which stoichiometric composition is used. Finally, Fig. 5d) shows that the TE monoliths did exhibit shrinkage upon drying, causing cracks and detachment from the channel walls. All monoliths should therefore be filled with DDW and sealed to prevent drying if not used immediately.

Size distribution of bead-liked TE monoliths. Bead uniformity and monodispersity are highly desirable for chromatographic applications. Liu et al. recently demonstrated that enhancing the uniform structure, rather than increasing surface area, could improve chromatographic separation for small molecules on TY globular agglomerates. ${ }^{42}$ Fig. 6 shows a typical size distribution observed for synthesized S-TE monolith beads. The beads are highly regular with a relatively narrow particle size distribution. However, as previously shown in Fig. 4, the size of the beads as well as their packing density was highly dependent on the preparation conditions. Changing the beaker shape, stir bar size or mixing speed can

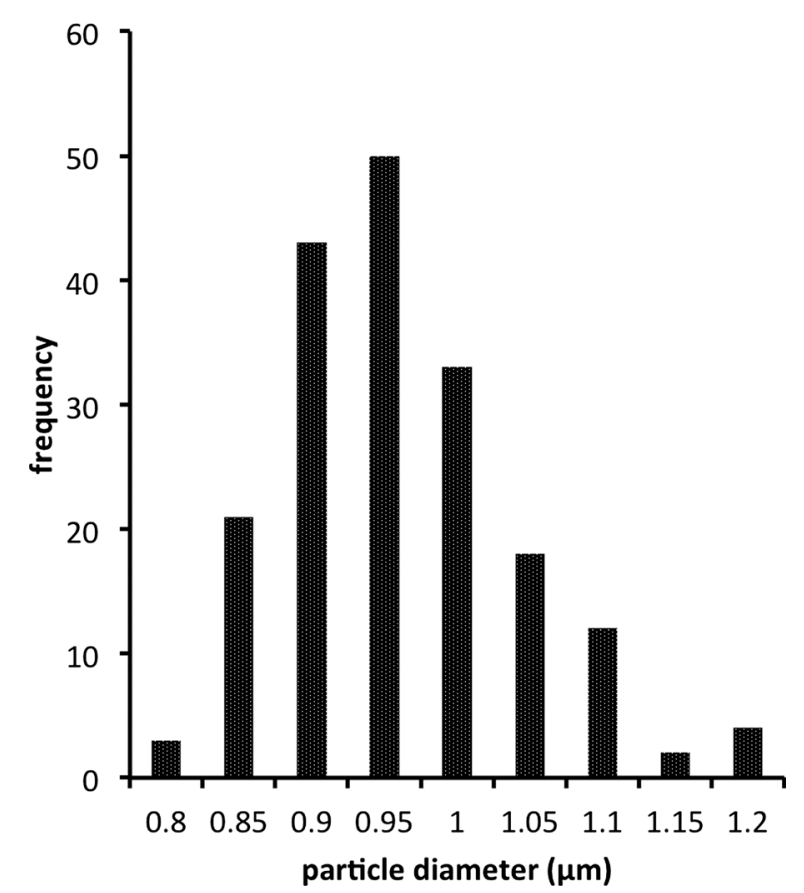

Fig. 6 Typical bead size distribution for a bead-like S-TE monolith prepared using $80 \% \mathrm{w} / \mathrm{w}$ methanol as the porogen.
Table 4 Population distribution for five bead-like S-TE monoliths prepared using $80 \% \mathrm{w} / \mathrm{w}$ methanol as the porogen

\begin{tabular}{lc}
\hline & Average size $^{a}(\mu \mathrm{m})$ \\
\hline Sample 1 & $1.4 \pm 0.2$ \\
Sample 2 & $0.98 \pm 0.08$ \\
Sample 3 & $1.2 \pm 0.2$ \\
Sample 4 & $1.05 \pm 0.07$ \\
Sample 5 & $1.2 \pm 0.1$ \\
& \\
& \\
&
\end{tabular}

all have an impact on the bead size produced, with a more vigorous stirring resulting in smaller beads. Table 4 shows the average particle size measured for five different S-TE monoliths prepared under similar conditions. Although the distributions are narrow, the means of the 5 populations are statistically different, highlighting the sensitivity of the process.

Specific surface area of bead-like TE monoliths. The specific surface area of the monoliths prepared with $80 \%$ and $60 \%$ methanol were $2.1 \pm 0.6 \mathrm{~m}^{2} \mathrm{~g}^{-1}$ and $1.8 \pm 0.6 \mathrm{~m}^{2} \mathrm{~g}^{-1}$, respectively. The small surface area indicates that the material was macroporous, with no or little micro- or mesopores. ${ }^{41}$ However, since the monoliths were cured in bulk rather than inside a TE microchannel and that they exhibit considerable shrinkage upon drying, the results obtained by Kr BET analysis are not an exact representation of the surface area of the monoliths prepared in much smaller quantities inside TE microfluidic channels. Still, the results are consistent with those obtained by Liu et al. $^{41}$ for similar organic-inorganic hybrid TE monoliths used successfully in capillary based liquid chromatography.

Galactose assay using the galactose oxidase enzymatic microreactor. Galactose oxidase was immobilized on OSTE-allyl monoliths (40\% excess ene) via TE click chemistry and ASA linkage. Additionally, the enzyme was incubated on unmodified OSTE-thiol, OSTE-allyl and S-TE monoliths to promote immobilization via disulfide bridges and to measure the magnitude of adsorption and non-specific interactions between the enzyme and the various TE monoliths. The term "unmodified" is used to describe monoliths without any prior surface treatment or modification, where a simple incubation was used to immobilize the enzyme of interest. As shown in Fig. S1, $\dagger$ the microreactors featuring enzymes immobilized via click chemistry and ASA linkage were significantly more efficient at converting the non-fluorescent ADHP into the fluorescent resorufin product then the unmodified TE microreactors. However, more in-depth investigations are necessary to determine whether the higher efficiency is due to a higher activity or a higher immobilization density of the ASAimmobilized enzyme on the monolith.

The presence of immobilized galactose oxidase on the unmodified TE monoliths is likely due to the formation of disulfide bonds between the free thiol groups present on the galactose oxidase cysteine side-chain and the thiol groups present at the surface of the TE monolith. Similarly, the irreversible adsorption of proteins (trypsin, cytochrome c, 
lysozyme, myoglobin and $\beta$-lactoglobulin) on thiolfunctionalized SBA-15 molecular sieves has been reported previously by $\mathrm{Yu}$ et $a l .{ }^{49,50}$ The assay results reported in Fig. S1† indicate that a significant amount of enzyme was immobilized at the surface of OSTE-thiol and S-TE monoliths, but also to a smaller extent at the surface of OSTE-allyl monoliths. These results indicate the likely presence of free unconverted thiol groups on S-TE and OSTE-allyl monoliths. Ellman's reagent (DTNB) was used to evaluate the thiol group density at the surface of TE substrates with various stoichiometric compositions. As seen in Fig. S2, $\dagger$ a significant number of free thiol groups are indeed present at the surface of S-TE polymers and even on OSTE-allyl polymers. Typically, in stoichiometric formulations it is expected that the thiol and ene components of the mixture will be consumed at identical rates. However, it is unlikely that monomer conversion is $100 \%$, so some leftover functional groups are expected at the surface of the monoliths. Additionally, homopolymerization of the ene monomers can alter the polymerization stoichiometry, leading to a higher conversion of the ene functional groups compared to the thiol functional groups. ${ }^{51}$ Cramer et $a{ }^{51}{ }^{51}$ have demonstrated that the conversion of the ene functional groups can be as much as $15 \%$ greater than that of the thiol functional group for the triallyl and tetrathiol monomers used here. These conversion results are consistent with the assay results reported in Fig. S1.†

Reduction of disulfide bonds for enzyme removal TE monoliths. Enzymes that were immobilized on the support only via a disulfide bond can be eluted from the monolith by incubation with TCEP, a reducing agent typically used to break disulfide bonds. After thorough flushing of the reactors with TCEP, most enzymes had been removed from the unmodified TE monoliths, with a conversion of ADHP into the fluorescent resorufin product down by $75-81 \%$. In contrast, the OSTE-allyl monoliths in which the enzymes had been immobilized via click chemistry and ASA linkage could not be regenerated via reduction with TCEP. A fluorescence intensity of $81 \%$ of the original value could still be obtained for the conversion of ADHP into the fluorescent resorufin after thorough flushing with TCEP. Therefore, the ASA

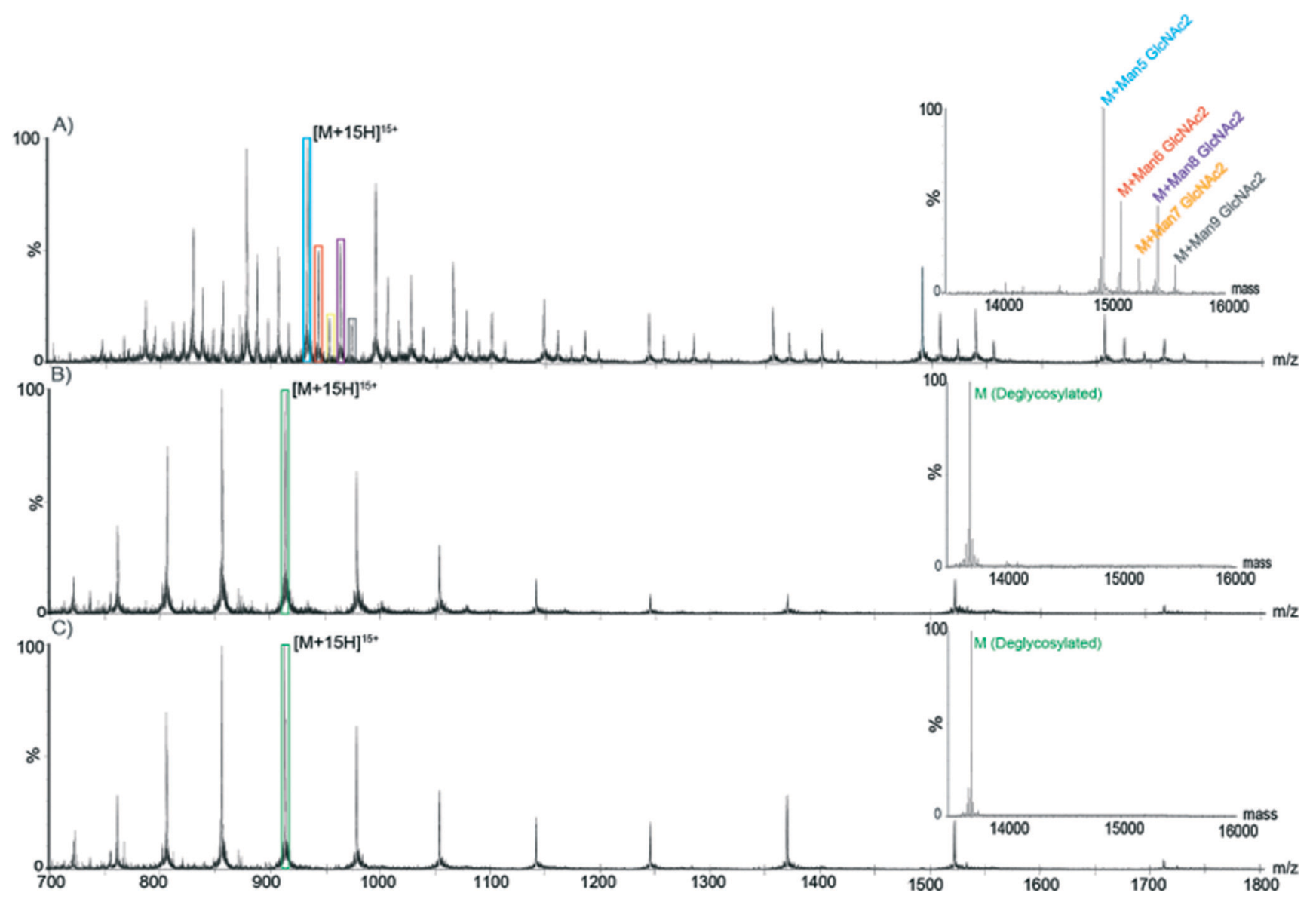

Fig. 7 On-chip deglycosylation of RNase B measured by LC-MS. A) Mass spectrum of glycosylated RNase B. [M $+15 \mathrm{H}]^{15+}$ is colored to indicate the five charge state distributions corresponding to the native glycoforms of RNAse B. The corresponding deconvoluted spectrum is shown in the insert using the same coloring scheme. B) Mass spectrum of RNase B deglycosylated off-chip by PNGase $\mathrm{F}$. $[\mathrm{M}+15 \mathrm{H}]^{15+}$ is colored to indicate the charge state distribution of the deglycosylated form of RNase B. The corresponding deconvoluted spectrum is shown in the insert using the same coloring scheme. C) Mass spectrum of RNase B deglycosylated online by PNGase F immobilized on a microfluidic chip via TE click chemistry and ASA linkage. $[M+15 H]^{15+}$ is colored to indicate the charge state distribution of the deglycosylated form of RNase B. The corresponding deconvoluted spectrum is shown in the insert using the same coloring scheme. 
linkage provides a strong, irreversible covalent immobilization of the enzyme while immobilization via disulfide bonds on unmodified TE monoliths featuring free thiol groups allows for easy regeneration of the monoliths.

Storage stability of the galactose-oxidase enzymatic microreactor. Although enzymatic reactors featuring galactose oxidase immobilized via click chemistry and ASA linkage could be re-used immediately with minimal decrease in activity, even after thorough flushing with TCEP, enzyme activity decreased significantly during storage as shown in Fig. S3.† Similar trends were observed both for never-used and re-used enzymatic microreactors after up to 13 days of storage in DDW at $4{ }^{\circ} \mathrm{C}$. Results indicate that optimally, the microreactors should be used within 4 days of their preparation. However, optimization of the storage conditions could improve the microreactor stability over time.

Deglycosylation of RNase B using the PNGase F enzymatic microreactor. PNGase $\mathrm{F}$ is a deglycosylation enzyme, which cleaves $\mathrm{N}$-linked carbohydrates. The activity of immobilized PNGase $\mathrm{F}$ was assessed using RNase B as a substrate. RNase $\mathrm{B}$ contains a single N-linked glycan at residue 60 and MS analysis of a reference sample of native glycosylated RNAse B showed the presence of five high-mannose RNase B glycoforms (with a structure of two $\mathrm{N}$-acetylglucosamines- and five to nine mannose monosaccharides). MS analysis of a reference sample of RNase B deglycosylated off-chip showed a single mass at $13692 \mathrm{Da}$, corresponding to the fully deglycosylated form of the protein. As shown in Fig. 7, RNase B samples processed with PNGase F both on- and off-chip yielded similar spectra, corresponding to the fully deglycosylated protein and the absence of any of the native glycoforms. Furthermore, similar on-chip deglycosylation was observed for chips employing either strategy for PNGase F immobilization.

\section{Conclusions}

Thiol-ene microfluidic platforms featuring emulsiontemplated porous monoliths show promise for applications such as enzyme microreactors, where a large surface area is necessary and it is paramount that the enzyme is strongly bound to the solid support. Highly uniform and monodisperse bead-like thiol-ene monoliths were prepared inside microfluidic channels. Curing and anchoring inside the microchannel was achieved in a single, rapid photoinitiated step without any prior surface modification. We have shown that immobilization of enzymes on the prepared monoliths via the formation of disulfides is straightforward and reversible. Alternatively, enzymes can be covalently and irreversibly immobilized via the free amino groups in their primary structure by means of ASA linkage. The prepared galactose oxidase and PNGase $\mathrm{F}$ microreactors demonstrated good enzymatic activity in a galactose assay and the deglycosilation of RNase $\mathrm{B}$, respectively. The prepared monoliths also offer promise as stationary phases for on-chip separations thanks to their narrow size distribution and the possibility to easily modify their surfaces with chemical groups for various retention modes.

\section{Acknowledgements}

Funding for this project was provided by the Danish Council for Independent Research - Technology and Production (grant no DFF- 4005-00341). Author S.S. acknowledges funding from Denmark's Advanced Technology Foundation (grant no 144-2013-6). Authors J.N. and G.N. gratefully acknowledge funding by the Erasmus program. Author J.N. acknowledges funding by the Grant Office project (GROFF, CZ.1.07/2.4.00/17.0106) and the Grant Agency of the Czech Republic (project P20612G014). Author K.D.R. acknowledge funding from the Marie Curie Actions Programme of the EU (grant no. PCIG09-GA-2011-294214) and the Danish Council for Independent Research - Natural Sciences (Steno Fellowship no. 11-104058). We acknowledge the Core Facility for Integrated Microscopy, Faculty of Health and Medical Sciences, University of Copenhagen as well as Dorthe Orbæk from the Department of Pharmacy (University of Copenhagen) for her help with SEM imaging. Finally we would like to thank Denis Okhrimenko from the NanoGeoscience Center (University of Copenhagen) for performing the surface area analyses.

\section{References}

1 J. Krenkova and F. Foret, Electrophoresis, 2004, 25, 3550-3563.

2 F. Svec, Electrophoresis, 2006, 27, 947-961.

3 J. Krenkova and F. Svec, J. Sep. Sci., 2009, 32(5-6), 706-718.

4 F. Svec and A. A. Kurganov, J. Chromatogr. A, 2008, 1184, 281-295.

5 J. Krenkova, F. Foret and F. Svec, J. Sep. Sci., 2012, 35, 1266-1283.

6 F. Svec, J. Chromatogr., B, 2006, 841, 52-64.

7 S. Xie, R. W. Allington, J. M. J. Fréchet and F. Svec, Adv. Biochem. Eng./Biotechnol., 2002, 76, 87-125.

8 H. Zhang and A. I. Cooper, Soft Matter, 2005, 1, 107.

9 M. S. Silverstein, Polymer, 2014, 55, 304-320.

10 C. Harrison, J. T. Cabral, C. M. Stafford, A. Karim and E. J. Amis, J. Micromech. Microeng., 2004, 14, 153-158.

11 P. Wägli, A. Homsy and N. F. de Rooij, Sens. Actuators, B, 2011, 156, 994-1001.

12 L.-H. Hung, R. Lin and A. P. Lee, Lab Chip, 2008, 8, 983.

13 B. Levaché, A. Azioune, M. Bourrel, V. Studer and D. Bartolo, Lab Chip, 2012, 12, 3028-3031.

14 S. H. Kim, Y. Yang, M. Kim, S.-W. Nam, K.-M. Lee, N. Y. Lee, Y. S. Kim and S. Park, Adv. Funct. Mater., 2007, 17, 3493-3498.

15 E. P. Dupont, R. Luisier and M. A. M. Gijs, Microelectron. Eng., 2010, 87, 1253-1255.

16 S. Silvestrini, D. Ferraro, T. Tóth, M. Pierno, T. Carofiglio, G. Mistura and M. Maggini, Lab Chip, 2012, 4041-4043.

17 B. T. Good, S. Reddy, R. H. Davis and C. N. Bowman, Sens. Actuators, B, 2007, 120, 473-480.

18 V. S. Khire, Y. Yi, N. A. Clark and C. N. Bowman, Adv. Mater., 2008, 20, 3308-3313.

19 C. F. Carlborg, T. Haraldsson, K. Öberg, M. Malkoch and W. van der Wijngaart, Lab Chip, 2011, 11, 3136-3147. 
20 J. P. Lafleur, R. Kwapiszewski, T. G. Jensen and J. P. Kutter, Analyst, 2013, 138, 845-849.

21 N. A. Feidenhans'l, J. P. Lafleur, T. G. Jensen and J. P. Kutter, Electrophoresis, 2014, 35, 282-288.

22 F. Saharil, C. F. Carlborg, T. Haraldsson and W. van der Wijngaart, Lab Chip, 2012, 12, 3032.

23 T. M. Sikanen, J. P. Lafleur, M.-E. Moilanen, G. Zhuang, T. G. Jensen and J. P. Kutter, J. Micromech. Microeng., 2013, 23, 037002.

24 C. E. Hoyle and C. N. Bowman, Angew. Chem., Int. Ed., 2010, 49, 1540-1573.

25 A. B. Lowe, Polym. Chem., 2010, 1, 17.

26 A. B. Lowe, C. E. Hoyle and C. N. Bowman, J. Mater. Chem., 2010, 20, 4745-4750.

27 P. Thirumurugan, D. Matosiuk and K. Jozwiak, Chem. Rev., 2013, 113(7), 4905-4979.

28 Y.-X. Chen, G. Triola and H. Waldmann, Acc. Chem. Res., 2011, 44, 762-773.

29 P. Jonkheijm, D. Weinrich, M. Köhn, H. Engelkamp, P. C. M. Christianen, J. Kuhlmann, J. C. Maan, D. Nüsse, H. Schroeder, R. Wacker, R. Breinbauer, C. M. Niemeyer and H. Waldmann, Angew. Chem., 2008, 120, 4421-4424.

30 V. Grazú, O. Abian, C. Mateo, F. Batista-Viera, R. FernándezLafuente and J. M. Guisán, Biotechnol. Bioeng., 2005, 90, 597-605.

31 Y.-H. Rogers, P. Jiang-Baucom, Z.-J. Huang, V. Bogdanov, S. Anderson and M. T. Boyce-Jacino, Anal. Biochem., 1999, 266, 23-30.

32 M. T. Neves-Petersen, T. Snabe, S. Klitgaard, M. Duroux and S. B. Petersen, Protein Sci., 2006, 15, 343-351.

33 W. W. Cleland, Biochemistry (Moscow), 1964, 3, 480-482.

34 E. Lovelady, S. D. Kimmins, J. Wu and N. R. Cameron, Polym. Chem., 2011, 2, 559-562.
35 S. Caldwell, D. W. Johnson, M. P. Didsbury, B. A. Murray, J. J. Wu, S. A. Przyborski and N. R. Cameron, Soft Matter, 2012, 8, 10344.

36 B. Sergent, M. Birot and H. Deleuze, React. Funct. Polym., 2012, 72, 962-966.

37 L. Kircher, P. Theato and N. R. Cameron, Polymer, 2013, 54, 1755-1761.

38 C. R. Langford, D. W. Johnson and N. R. Cameron, Polym. Chem., 2014, 5, 6200-6206.

39 X. Gong, W. Wen and P. Sheng, Langmuir, 2009, 25, 7072-7077.

40 R. A. Prasath, M. T. Gokmen, P. Espeel and F. E. D. Prez, Polym. Chem., 2010, 1, 685-692.

41 Z. Liu, J. Ou, H. Lin, Z. Liu, H. Wang, J. Dong and H. Zou, Chem. Commun., 2014, 50, 9288-9290.

42 Z. Liu, J. Ou, H. Lin, H. Wang, Z. Liu, J. Dong and H. Zou, Anal. Chem., 2014, 86, 12334-12340.

43 S. Brunauer, P. H. Emmett and E. Teller, J. Am. Chem. Soc., 1938, 60, 309-319.

44 G. L. Ellman, Arch. Biochem. Biophys., 1959, 82, 70-77.

45 P. W. Riddles, R. L. Blakeley and B. Zerner, in Enzyme Structure Part I, Academic Press, 1983, vol. 91, pp. 49-60.

46 A. J. D. Magenau, J. W. Chan, C. E. Hoyle and R. F. Storey, Polym. Chem., 2010, 1, 831.

47 A. Patton and P. Chism, Anal. Chem., 1951, 23, 1683-1685.

48 J. Tiller, P. Berlin and D. Klemm, Biotechnol. Appl. Biochem., 1999, 30, 155-162.

49 H. H. P. Yiu, C. H. Botting, N. P. Botting and P. A. Wright, Phys. Chem. Chem. Phys., 2001, 3, 2983-2985.

50 H. H. P. Yiu, P. A. Wright and N. P. Botting, J. Mol. Catal. B: Enzym., 2001, 15, 81-92.

51 N. B. Cramer and C. N. Bowman, J. Polym. Sci., Part A: Polym. Chem., 2001, 39, 3311-3319. 